\title{
A Methodology for Risk Assessment and Management for SMR Nuclear Power Plant Hit by High Explosive Warheads
}

\author{
Igal M. Shohet ${ }^{1}$, Sima Michal Elkabets ${ }^{1}$, David Ornai ${ }^{1}$, Yosef Kivity ${ }^{1}$, Erez Gilad ${ }^{2}$, \\ Robert Levy', Gal Shany ${ }^{1}$, Matan Levi-Tzedek ${ }^{1}$, Barak Tavron ${ }^{3}$ and Gabi Ben-Dor ${ }^{4}$
}

1 Department of Structural Engineering, Ben-Gurion University of the Negev, Beer Sheva, Israel

2 Nuclear Engineering Unit, Ben-Gurion University of the Negev, Beer Sheva, Israel

3 Planning Development and Technology Division, Israel Electric Corporation, Haifa, Israel

4 Department of Mechanical Engineering, Ben-Gurion University of the Negev, Beer Sheva, Israel

\begin{abstract}
Within its 2050 energy plan, Israel examines the demographic implications of a Nuclear Power Plant (NPP) in Shivta Rogem site in the Negev. NPP would have a great contribution to the diversity and robustness of energy sources in Israel. A Small Modular Reactor (SMR) is designated to be safer than existing NPPs and will have better resistance to external hazards due to inherent passive safety features. This study develops a risk assessment methodology for a Nuclear Power Plant (NPP), in particular, SMR, to withstand a large conventional warhead explosion (GBU-28). The methodology comprises: hydro-dynamic simulations, validation of the dynamic simulations using numerical analysis compared to the simulations, risk analysis and damage assessment given the reference scenario of a detonation of a GBU-28 inside the underground water pool of a NuScale SMR. Discrete fragility curves were developed to evaluate the capacity of the SMR critical components. The overall probability of failure was assessed based on a Fault-Tree-Analysis (FTA). Results of the $3 \mathrm{~m}$ explosion from the reactor bay wall showed a displacement of $13 \mathrm{~cm}$, breaching of the SMR bay wall and the water pool wall, and $12 \mathrm{~cm}$ deflection of the Containment Vessel (CNV). Sensitivity analyses of the uncertainty values were carried out by posting HCLPF (High Confidence Low Probability of Failure) values to the fragility curves. Combination of the results of the study with the failure criteria of NuScale for seismic hazards reveals that given the hazard scenario, core damage is expected accompanied by release of radioactive materials to the atmosphere. The study concludes that building the SMR in Israel will require adapted protective solutions. Future research may examine protective alternatives such as adding a reinforced concrete protecting layer or the possibility to set the SMR at a deeper underground elevation.
\end{abstract}

(c) 2020 The Authors. Published by Budapest University of Technology and Economics \& Diamond Congress Ltd Peer-review under responsibility of the Scientific Committee of the Creative Construction Conference 2020.

Keywords: explosions, fragility curves, resilience, risk management, SMR

\section{Introduction}

The demand for energy across the world is constantly rising. Energy can be derived from a variety of sources; limited sources such as fossil fuels or renewable sources such as solar, hydroelectric and wind energy. Another significant source of energy is nuclear energy. Ronen [1] stated that while renewable energies are perceived by the public as cleaner than nuclear energy, nuclear energy has its advantages. "Energy Density" is the amount of area needed for the production of an energy unit. Nuclear energy has significantly higher energy density than renewable energies; and therefore is preferred. Despite its advantages, a significant disadvantage of nuclear energy is long-lived radioactive waste after a Nuclear Power Plant (NPP) activity is decommissioned, leading to a high life cycle cost. Production of nuclear energy 
is economic, cost-effective and has clear environmental benefits [1]. It can diversify energy sources, reduce greenhouse gases emissions and ensure the robustness to the energy economy [2]. A NPP failure would have severe economic, environmental and social consequences. Thus, the need to assure the plant's ability to withstand extreme events in general and the threat scenario in particular is obvious. According to Ornai et al. [3], an extreme event of a direct missile hit could lead to an overall failure of the NPP, which in turn could lead to core meltdown followed by the release of radioactive materials.

\subsection{Research rationale and objectives}

The research followed twofold objectives:

- Damage assessment of the threat scenario: review of failure modes representing the vulnerability of the SMR to the threat scenario. The prospected outcomes of the research include a comprehensive review of the state-of-the-art of the NuScale SMR technology with respect to the resilience of the SMR to an external event of munition hit causing internal explosions.

- Risk analysis according to the threat scenario. Definition of probabilistic values and development of fragility curves for critical components of the NPP to the threat scenario. The novelty of the research lays in the integrated methodology that combines: adapted fragility curves based on seismic data taken from NuScale's SMA, hydro-dynamic simulations, validation and sensitivity analyses. This allows for high validity of the risk analysis and provides a tool for assessment.

\section{Vulnerability of the NPP to core damage and large release to explosive warhead hit}

\section{1. $S M R$}

SMR stands for either Small Modular Reactor or Small and Medium Reactor, with an output of 300-700 MWE. Its main economic advantage is based on full factory manufacturing and short construction period. Other advantages are its passive safety systems, the possibility to install it underground and the long periods between refueling. SMRs are based upon positioning all the components of the steam generation system integrally inside the prefabricated reactor vessel, to decrease manufacturing cost and to improve safety [4]. In the Westinghouse SMR for example, all safety systems which demand an electrical source, were changed to those based on passive physical principles such as - gravity, circulation, evaporation, condensation, or convection [5]. Smith \& Wright [6] determined that underground positioning of the Westinghouse SMR decreases the chance to an event, which will affect the safety of the SMR and, that the passive safety systems can safely stop the nuclear reaction, remove the decay heat and ensure cooling and safe system shutdown in case of an emergency event.

\subsection{NuScale SMR}

The NuScale SMR is a modular PWR NPP, consists of up to 12 modules. Each module consists of a 45 MWE reactor and 2 steam generators. The nuclear fuel is $\mathrm{UO} 2$ enriched up to $4.95 \%$ and the duration of the fuel life cycle is 24 months. An optional configuration is 540 MWE for 12 modules. Most of the NPP main building is underground, made of high stiffness concrete structure to address earthquakes and aircraft crash impact scenarios. Each power module includes a containment and a reactor vessel, interior helical coil, two steam generators and a pressurizer, all factory manufactured [7]. Each module is installed in its own isolated bay in an underground, stainless steel-lined concrete pool, also referred as Ultimate Heat Sink (UHS).

\subsection{NuScale SMR geometry}

Due to security-related issues the geometry of NuScale SMR reactor building is not available for the open public. However, NuScale had published in Chapter 3 "Design of Structures, Systems, Components and Equipment" [8], sufficient data about the finite-element modeling used for estimating the dynamic loadings on the building and for seismic design. The finite-element models provide information such as walls length, walls thickness, building height and more. The most relevant geometrical data is presented in Table 1. 
Table. Nuscale SMR reactor building and module dimensions.

\begin{tabular}{lclc}
\hline & Reactor building (RXB) & \multicolumn{2}{c}{ Module } \\
\hline Parameter & Dimension [m.] & Parameter & Dimension [m.] \\
\hline Total Height & $\sim 50.9$ & Height & $\sim 19.8$ \\
Total length & $\sim 106.7$ & Diameter & $\sim 4.4$ \\
Total width & $\sim 45.7$ & Thickness & $\sim 0.076$ \\
Ceiling thickness & $\sim 1.2$ & & \\
Floor thickness & $\sim 3.0$ & & \\
Pool height & $\sim 23$ & & $\sim 106.7 \mathrm{~m}$ \\
Depth below ground & $\sim 26.2$ & & \\
\end{tabular}

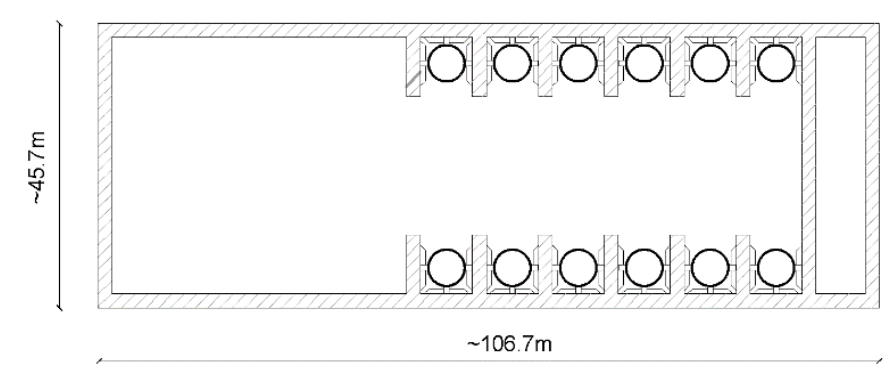

Figure 1: RXB horizontal cross-section - no to scale

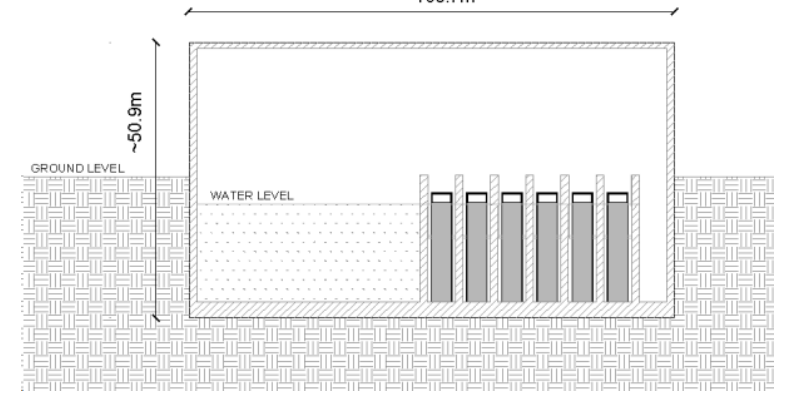

Figure 2: RXB vertical cross-section - not to scale

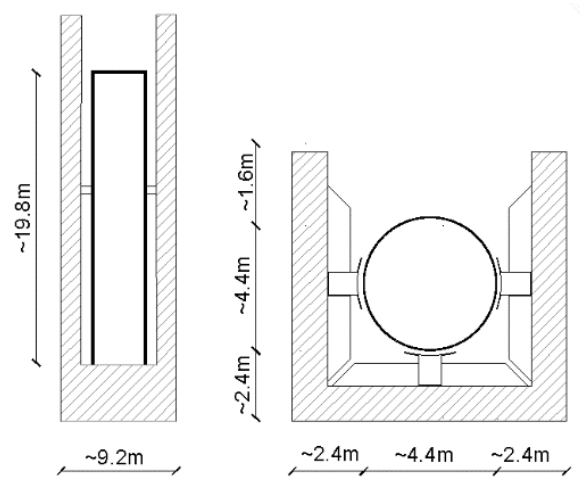

Figure 3: Module cross-sections - not to scale

\subsection{External hits on NPP - missile hit}

\subsubsection{Missile hit on an NPP}

Shohet et al. [9] examined munition hit of a GBU-28 missile on a Westinghouse AP-1000 NPP. Risk analysis and damage assessment were carried out and included specific definition of the threat scenario and analysis of the loads and impacts on the structure as a result of a nearby explosion. A method was developed to assess the vulnerability of the NPP's components due to the generated shock, according to existing data regarding aircraft impact. As part of the research, existing fragility curves (developed originally to evaluate seismic performances) were adapted and used to conduct a PRA, showing a large probability for LOCA scenario as a result of damage to critical components.

\subsubsection{External hits on NPP - aircraft impacts}

Lo Frano \& Forasassi [10] examined, using FE models, the impact considerations of a commercial aircraft (Boeing 747) and a fighter jet (Phantom F4) on the containment structure of a Gen-III NPP, and conducted sensitivity analyses to improve the shielding of the containment. The research offered methods to improve the protection, such as enlarging the thickness of the concrete walls, increasing the quantity of reinforcement bars, increasing the usage of pre-stressed concrete and more. Saberi et al. [11] examined, using FE models, the impact of commercial aircrafts (Boeing 707 and Airbus A-320) and a fighter jet (Phantom F4) on different locations of the Reactor Core Containment Vessel (RCCV) of a Gen-III NPP. It was 
found that a hit on the center of the RCCV made the largest deformation of the concrete wall of the RCCV but would not cause a critical failure to the NPP.

\section{Aircraft impacts on NuScale SMR}

Since NuScale SMR is a new technology, very few studies regarding aircraft impacts on NuScale SMR were found and thus, the research entitled "Aircraft Impact Considerations for NuScale SMR Plant Design", by James et al. [12], was reviewed carefully. The goal of the research was to show that in case of a hit, either the primary containment system is not damaged in any way or the reactor core remains cooled, and either spent fuel cooling or spent fuel pool maintain their integrity. These goals are similar to the desired end state for a GBU-28 hit scenario. Methodology Two methods were employed to represent aircraft impact: Riera's method using a force time history applied over a representative contact area [13]. Missile-TargetInteraction method where a model of the impacting aircraft is included in the analysis [12]. The methodology included structural analyses, i.e. modeling of the reinforced concrete, and in addition, a fire and shock effects assessment was carried out, to determine if sufficient SMR SSCs (Structures Systems and Components) remain operational to ensure heat removal and core cooling. It was found that NuScale SMR would most likely achieve the goals above, meaning in case of an impact, the reactor core would remain cool and the spent fuel pool would remain intact. The loadings were considered sensitive information and could not be discussed in the research, which led us to analyze this paper in a qualitative and methodic point of view.

\subsection{Earthquakes}

Markou \& Genco [14] developed 3D models and performed a finite element \& nonlinear analysis to evaluate the seismic resistance of the reinforced concrete reactor building structure of the NuScale SMR to high seismic loads. Models were constructed on SAP2000 (2018) and Reconan FEA (v.1.00, 2010). Overall, the NuScale SMR reactor building was found to be earthquake proof due to its structural integrity and underground configuration. The reference scenario was Chile's 2010 earthquake which is the second strongest in magnitude of Chile's seismic history, documented a maximum recorded PGA of $0.93 \mathrm{~g}$ and a corresponding $5 \%$ damped peak structural acceleration of $1.73 \mathrm{~g}$ for structures with a period of $0.1 \mathrm{sec}$. Dimensions have been evaluated from different sources (deviations between the two studies appear due to the gloomy data derived from the withheld information). Evaluation made according to Eurocode 8, assuming type "B" soil. The weight of the building above ground level was evaluated as $\sim 150,000 \mathrm{kN}$.

\subsection{Conclusions of the review}

In NuScale SMR, a direct aircraft impact on the spent fuel pool and on the steam supply system could not occur due to its location underground. In addition, SMR designs have both advantages and disadvantages compared to conventional NPPs regarding aircraft impact: SMRs are less likely to be hit since the reactor vessels and containment are placed underground and due to the small size, it is easier and less costly to create a hardened and protected structure. However, the smaller size also means that transmission of shock through the structure could cause simultaneous damages, while in a larger NPP, components are located physically apart, and the risk for a comprehensive damage is smaller.

\section{Methodology}

Figure 4 delineates a 7-phase risk analysis and damage assessment methodology. The methodology uses Probabilistic Risk Analysis (PRA), Nuscale Seismic margin Analysis (SMA), and Fault-Tree-Analysis along with dynamic simulations and Fragility Curves for the damage assessment. 


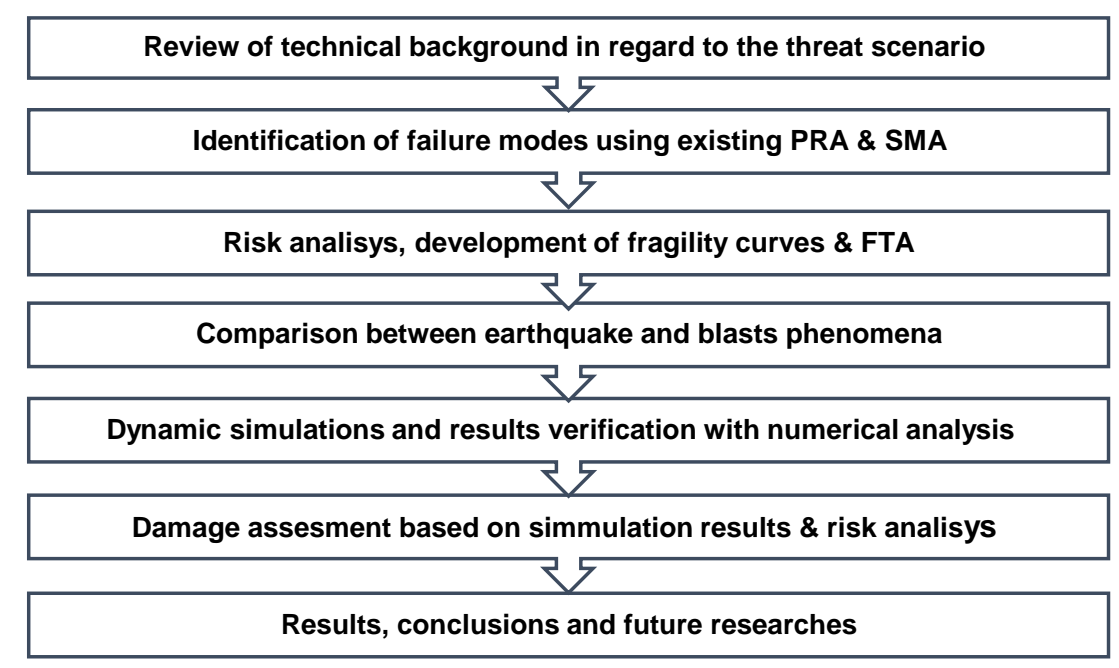

Figure 4: Risk analysis methodology

\subsection{Material properties}

- Concrete: Ec of $30 \mathrm{GPa}$ and compressive strength of $50 \mathrm{MPa}$, Poisson ratio V = 0.2;

- Steel reinforcement: Es of $190 \mathrm{GPa}$ and yielding stress of $500 \mathrm{MPa}$.

\subsection{Fault-Tree-Analysis (FTA) describing the postulated event}

A standard FT was developed to graphically describe the failure mechanisms due to given damages to structural elements and consequently deduce their impact on the overall failure of the facility. Failure of structural elements are defined as the basic events in this FT, and CD is the top event. It is a simple FT without intermediate events. Figure 4 presents a FT of the failure mechanisms yielding "core damage" top event. In this FT the cutsets are short which in a qualitative analysis may indicate high vulnerability of the system. Though, this FT does not model all the possible scenarios of the system failure - rather, it focused only in the most vulnerable elements exposed to the severe scenario of a direct interior GBU-28 hit selected for this research. The FT is made of 5 "OR" gates meaning the probability is calculated as the union of all basic events using "The Morgan's Law" as described in Equation 1:

$$
\begin{gathered}
P(\text { Failure })=P\left(E_{1} \mathrm{UE}_{2} \mathrm{UE}_{3} \mathrm{UE}_{4} \mathrm{UE}_{5}\right) \\
=1-P \overline{\left(E_{1} \cup \mathrm{E}_{2} \mathrm{UE}_{3} \mathrm{UE}_{4} \mathrm{UE}_{5}\right)} \\
=1-\mathrm{P}(\overline{\mathrm{E} 1} \cdot \overline{\mathrm{E} 2} \cdot \overline{\mathrm{E} 3} \cdot \overline{\mathrm{E} 4} \cdot \overline{\mathrm{E} 5}) \\
=1-\mathrm{P}(\overline{\mathrm{E} 1)} \cdot \mathrm{P} \overline{(\mathrm{E} 2)} \cdot \mathrm{P} \overline{\mathrm{E} 3)} \cdot \overline{\mathrm{P}} \overline{\overline{\mathrm{E}} 4)} \cdot \mathrm{p} \overline{(\mathrm{E} 5)} \\
=1-[(1-\mathrm{P}(\mathrm{E} 1)) \cdot(1-\mathrm{P}(\mathrm{E} 2)) \cdot(1-\mathrm{P}(\mathrm{E} 3)) \cdot(1-\mathrm{P}(\mathrm{E} 4)) \cdot(1-\mathrm{P}(\mathrm{E} 5))]
\end{gathered}
$$

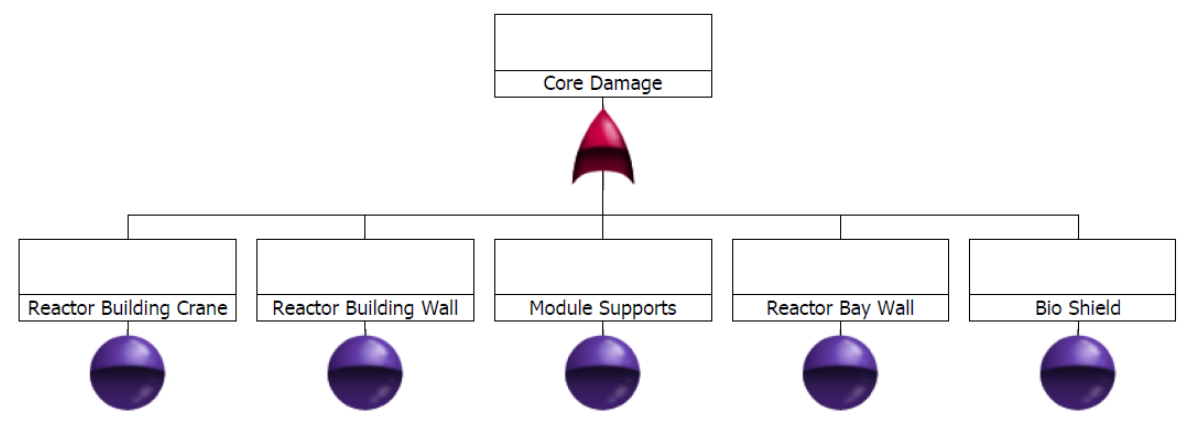

Figure 5: GBU-28 hit FTA 


\subsection{Discrete Fragility Curves}

We can assume that the aiming point of aerial attack using GBU-28 will be the center of the reactor building (RXB), and around it we can define circular aerial rings with different radii for example at $1 \mathrm{~m}$ range (Fig. 6). The Circular Error Probability (CEP) is defined as the radius of the circular area around the aiming point in which $50 \%$ of the launched munition will hit. Each ring has a relative hit percentage according to its location and area according to the CEP radial distribution. The hit probability sum of all the rings is 0.5 (for half of the RXB). Each ring divided into ring segments of about 1 sq.m. Due to the building longitudinal symmetry, only half of the building should be analyzed in the latitudinal direction.

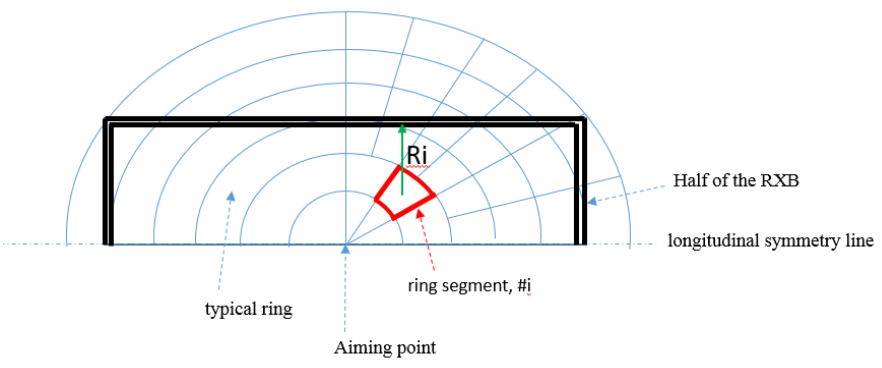

Fig. 6 Arial distribution to rings and square segments

Each ring segment $\mathrm{i}$ has the following characteristics: 1) a center, 2) a certain munition hit probability calculated by its relative part in its circular ring area- $\mathrm{Pi}, 3$ ) the relative structural damage (in percentage)- SDij(\%) caused to each of the SMR $\mathrm{j}$ critical components according to the distance (and also the angle can be considered) between the ring segment center and the critical SMR object.

The structural damage at different $k$ levels, $\operatorname{SDk} \%(k=1,2,3)$ is defined according to the relative structural element supports' rotation and the ductility, $\mu$ (equals to dynamic deflection divided by elastic deflection of the wall mid span) based on UFC3-340-02 [15]: SD $\%$ for cracking, $\mathrm{SD}_{2} \%$ for elastic limit, $\mathrm{SD}_{3} \%=100 \%$ for failure. In case of structural element with shear reinforcement, the failure is expected at supports' rotation of $4^{\circ}$, and the resulted ultimate deflection will be defined as $\mathrm{SD}_{3} \%=100 \% . \mathrm{SD}_{2} \%$ and $\mathrm{SD}_{3} \%$ are equal to the mid span deflections at cracking and at the elastic limit divided by the ultimate deflection respectively. Summation of all the ring segments with the same structural damage definition for each critical SMR object yields the various Structural Damage levels, SDk, versus the Structural Damage Probability $\left(\mathrm{SDP}_{\mathrm{k}} \%\right)$ caused by a single attack scenario. For each critical SMR object \#j the Structural Damage Probability at certain level $\mathrm{k}$ (such as the pool wall) SDP $\mathrm{j}_{\mathrm{k}, \mathrm{k}}(\%)$ will be calculated according to Eq. 2.

$$
S D P_{j, k}=\frac{2}{T R A} \sum_{\forall i} R S i, k \cdot H P i
$$

The constant two in the nominator considers the symmetry and it is multiplied by the sum of the product of all the ring segments areas \#i with the Structural Damage levels SDk\% (RS $\left.\mathrm{R}_{i, k}[\mathrm{~m} 2]\right)$ and their hit probability $\left(\mathrm{HP}_{\mathrm{i}}[\%]\right)$, all divided by the total rings area (TRA [sq.m.]. It yields the qualitative fragility curve presented in Fig. 7. As CEP is getting smaller $\mathrm{SDP}_{\mathrm{k}}$ values are growing, means that the risk is higher.

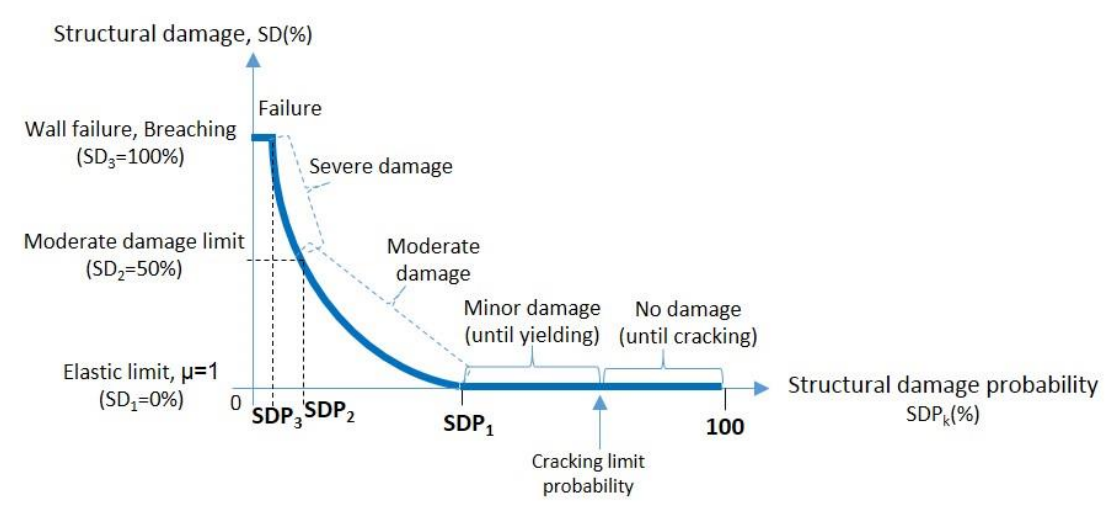


Fig. 7: Fragility curve of the reactor bay wall

\section{Results}

\subsection{Scenario no. 1 -Blast effects on the CNV Description}

- The bomb axis of symmetry is vertical and parallel to the CNV;

- Distance of $3 \mathrm{~m}$ from the CNV;

- Bomb centre at $5 \mathrm{~m}$ above the pool floor.

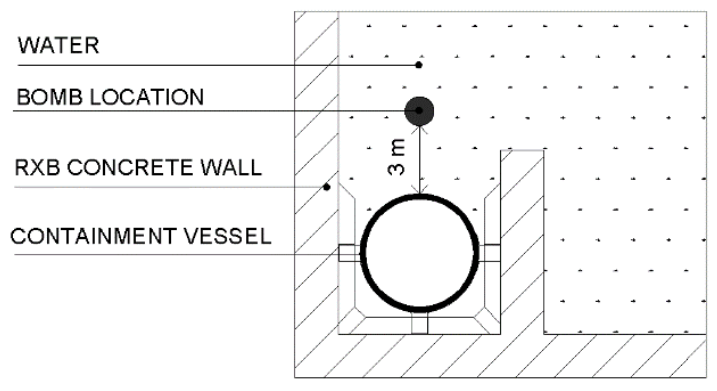

Figure 8: Description of scenario no. 1 (horizontal cross-section, not to scale)

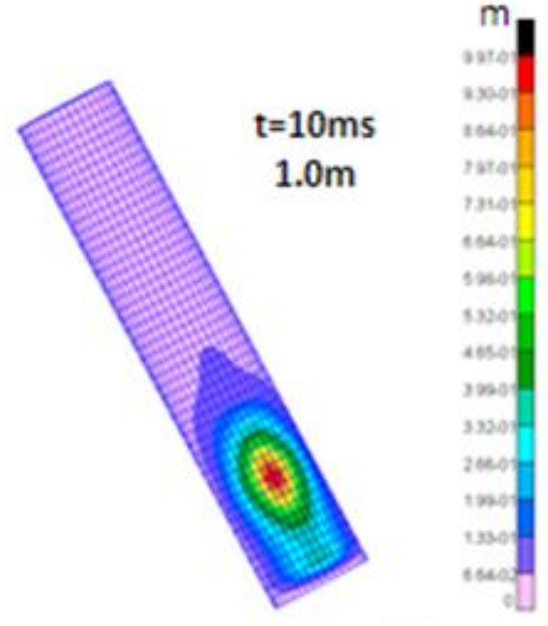

Figure 9: Scenario no. 1Displacement map of the CNV surface

Summary of scenario no. 1

"A preliminary analysis of GBU-28 explosion within the water pool of the SMR nuclear power plant shows that at a distance of $3 \mathrm{~m}$ between the bomb and the containment longitudinal axis a severe deformation of the containment exterior wall is expected to occur."

Results of scenario no. 1

- Maximum displacement of $\sim 1.0 \mathrm{~m}$ is created in the CNV.

- Over-Pressures of 1000 bar were created for short periods.

4.2. Scenario no. 2 - Blast effects on the external walls of the RXB - Description

- The bomb axis of symmetry is vertical;

- Distance of $3 \mathrm{~m}$ from the internal sidewall (not supported by earth on its rear side);

- Bomb centre at $5 \mathrm{~m}$ above the pool floor.

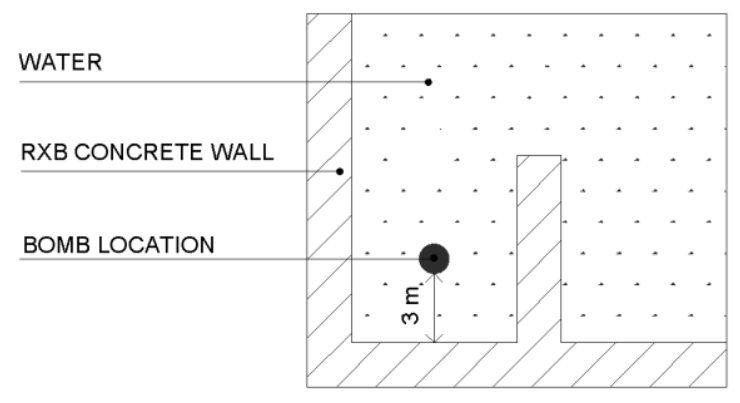

Figure 10: Description of scenario no. 2 (horizontal cross-section, not to scale) 


\section{Summary of scenario no. 2}

"A simulation of bomb explosion within the water pool shows that a massive breaching of the concrete walls may occur. The present simulation was carried out under the assumption that the walls of the pool are above ground. This pertains to an explosion near the upper surface of the pool. It can be assumed, based on the present results, that breaching would occur also when the walls are below surface, i.e. supported by external earth cover. In order to validate this assumption, an additional simulation is required."

Results of scenario no. 2

The peak acceleration was found to be $\sim 4860 \mathrm{~g}$.
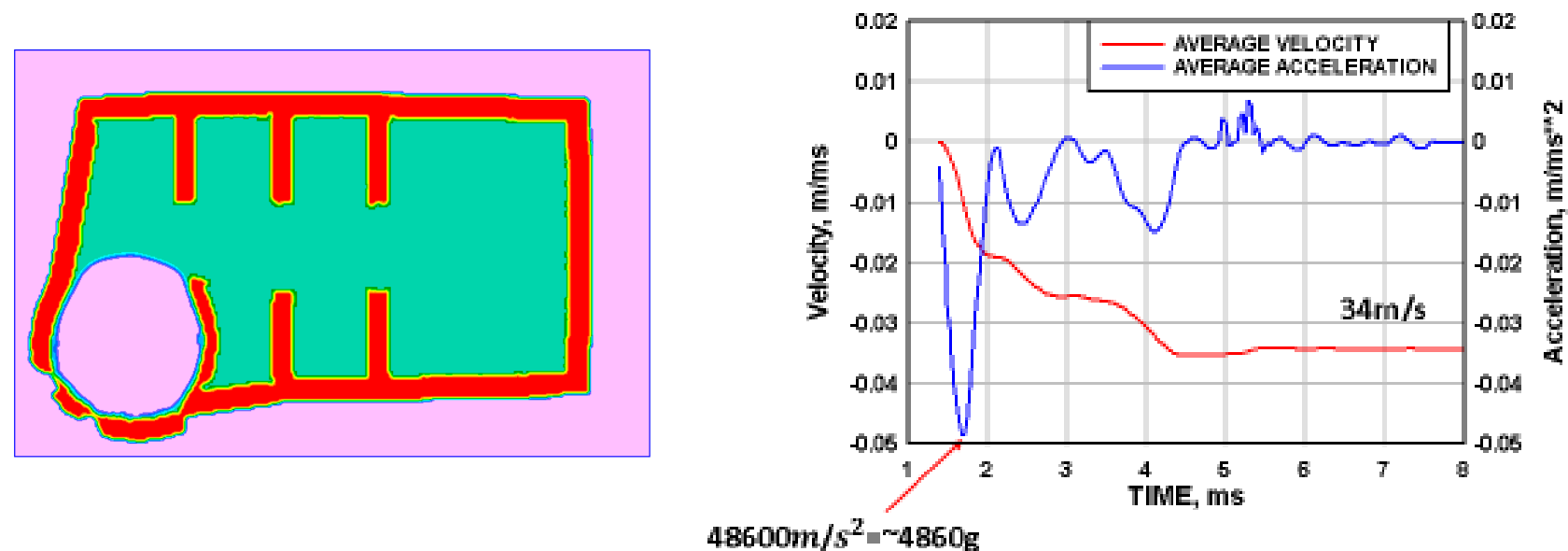

\section{$48600 \mathrm{~m} / \mathrm{s}^{2} \approx \sim 4860 \mathrm{~g}$}

Figure 11: Scenario no. 2 - density map at 120ms - massive wall Figure 12: Scenario no. 2 - wall velocity and acceleration for the deformations first $8 \mathrm{~ms}$

It means that the pool water content will leak and radioactive materials can reach the atmosphere and the surrounding ground.

\subsection{Scenario no. 3 - Blast effects on the Bay Wall}

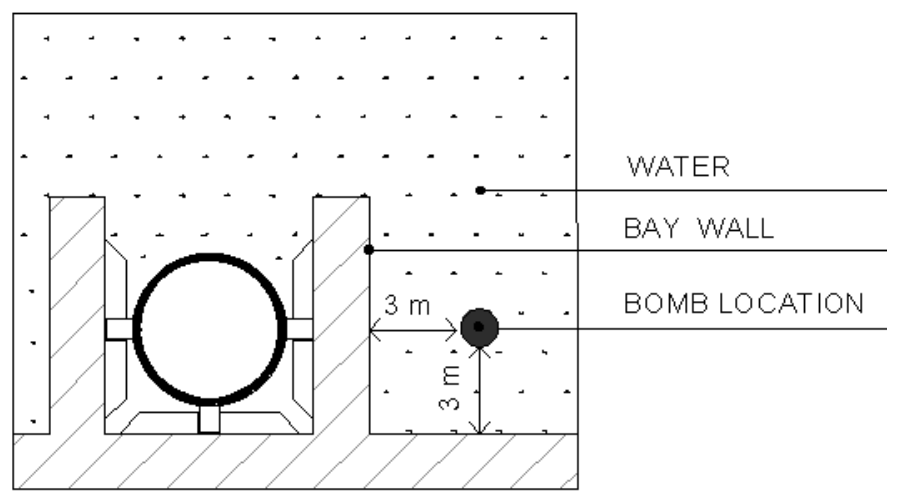

Figure 13: Description of scenario no. 3 (horizontal cross-section, not to scale)

\section{Description}

- The bomb axis of symmetry is vertical;

- Distance of $3 \mathrm{~m}$ from the sidewall and from the Bay Wall.

- Bomb centre at $5 \mathrm{~m}$ above the pool floor. 


\section{Summary of Scenario no. 3}

"A simulation of bomb explosion within the water pool shows that a massive breaching of the concrete walls may occur. The present simulation was carried out under the assumption that the walls of the pool are above ground. This pertains to an explosion near the upper surface of the pool. It can be assumed, based on the present results, that breaching would occur also when the walls are below surface, i.e. supported by external earth cover. In order to validate this assumption, an additional simulation is required."

\section{Results of scenario no. 3}

The computer model showed severe breaching of the bay wall and pool wall as a result of the scenario. The Maximum displacement of the CNV was found to be $12 \mathrm{~cm}$. By the dynamic analysis, the maximum bay wall displacement was found to be $14.6 \mathrm{~cm}$.

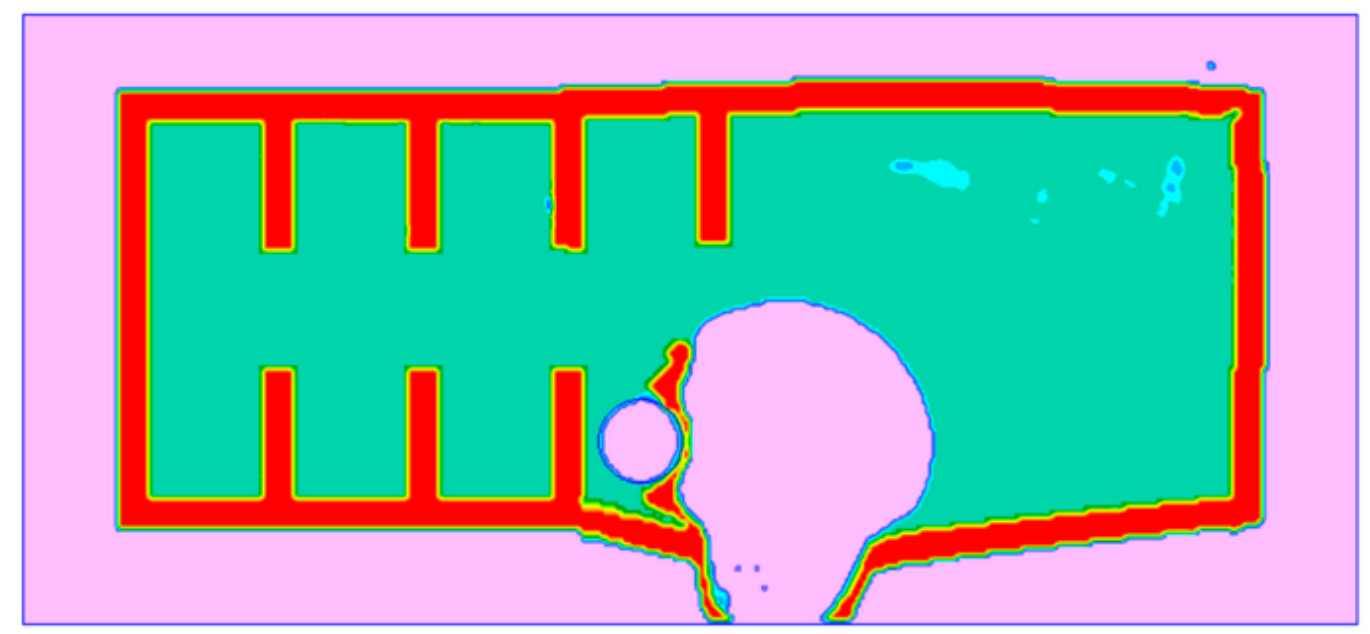

Figure 14: Scenario no. 3 - density map at 190ms - Breaching of the pool and the baywall acompanied by $12 \mathrm{~cm}$ deflection of the CNV.

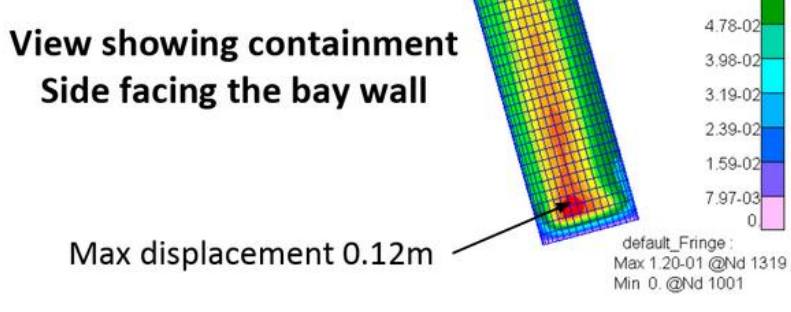

Figure 15: Scenario no. 3- displacement map of the CNV surface at $190 \mathrm{~ms}$ (Shohet et al, 2019)

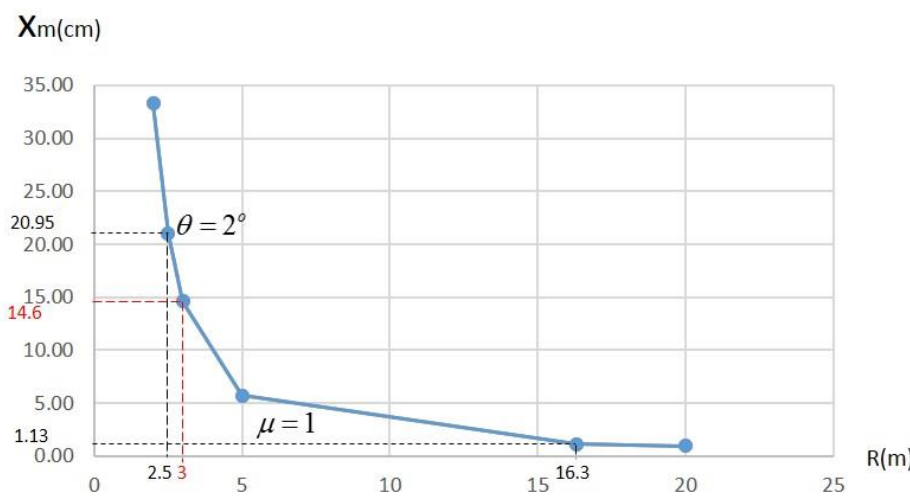

Figure 16: Scenario no. 3- dynamic deflection of the bay wall as a function of the distance from the underwater explosion.

\subsection{Sensitivity analyses}

The uncertainty of the design parameters were not detailed in the design documents. A best estimate was given for the fragility curve based on the $\beta$ values and median acceleration given for the HCLPF. Fragility curves depend on the value of the median and are a function of the randomness. In order to improve the 
results and demonstrate the influence of the randomness, sensitivity tables using different values of $\beta$ were carried out.

Table 2: sensitivity analysis for uncertainty values of the reactor bay wall (E2) failure to $\beta$

\begin{tabular}{cccc}
\hline$\beta$ & $P$ (failure) $2 \mathrm{~g}$ & $\mathrm{P}$ (failure) $4 \mathrm{~g}$ & $\mathrm{P}$ (failure) $6 \mathrm{~g}$ \\
\hline 0.28 & 0.33 & 0.98 & 1.00 \\
\hline 0.38 & 0.37 & 0.93 & 0.99 \\
\hline 0.68 & 0.40 & 0.88 & 0.98 \\
\hline
\end{tabular}

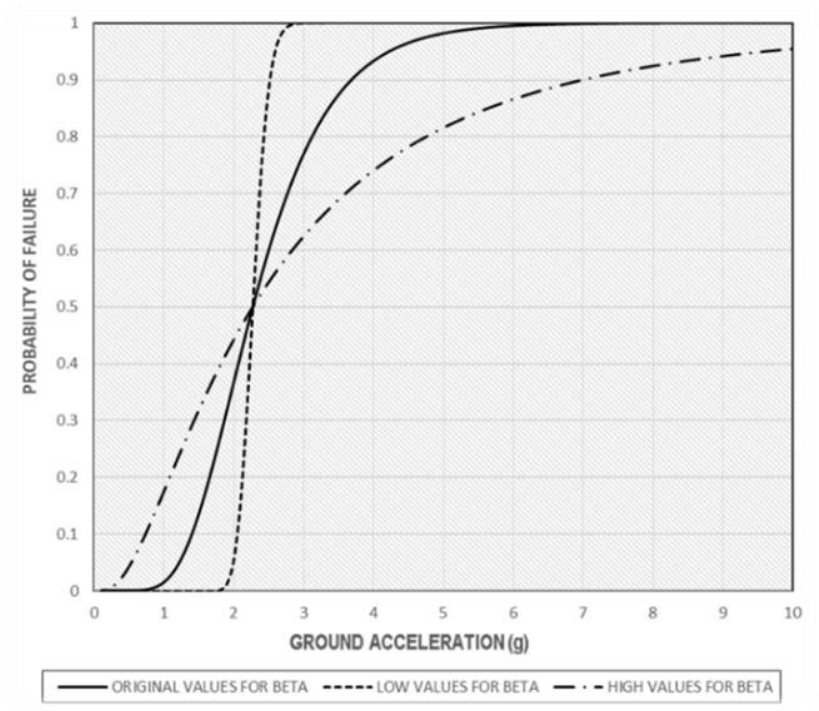

Figure 17: Reactor bay wall cumulative density function

\subsection{Results of the sensitivity analyses}

The higher $\beta$ is, the larger the spread is - results emphasis the function of $\beta$ as a measure of uncertainty. The highlighted $\beta$ on Table 2 presents the original value taken from the SMA and its results are identical to the analysis carried out in this research. Similar sensitivity analyses were carried out to other critical components such as reactor building wall, power module supports, etc.

\section{Conclusion and Discussion}

The resilience of the SMR's structural elements (according to fragility curves developed in this reasarch for the scenario) is limited to $0.72 \mathrm{~g}$ which resonably suites NuScale's result of $0.88 \mathrm{~g}$ as described in the SMA results. The degradation of $\sim 20 \%$ in the resilience could be explained either by the meticulous logic taken for the FTA in comparison to the min-max method used by the designers, or due to inaccuracies due to the reconstructed fragility curves developed in this research based on partial data and assumptions. Higher accelerations would cause core damage and a release of radioactive materials to the atmosphere. Therefore, the NuScale SMR cannot withstand external events resulting in long duration ground motions higher than $0.72 \mathrm{~g}$. In order to achieve reliable capacity parameters for explosions, extremely high cost and well-designed experiments must be carried out.

A scenario of GBU-28 detonation at a distance of $3 \mathrm{~m}$ from the bay wall was examined. Simulation's results showed maximum deflection of the CNV was $12 \mathrm{~cm}$ and breaching of the bay wall and the pool wall. It was verified by dynamic calculation (equating blast kinetic and the bay wall strain energy) showed maximum bay wall displacement of $14.6 \mathrm{~cm}$ (see Scenario No. 3). These results, with regard to NuScale analysis for seismic events determine the consequences of the scenario as core damage and release of radioactive materials to the atmosphere - "The SMA assumes that failure of major structures leads to sufficient damage to the modules such that core damage and a large release would result." [16]. These findings leads to the conclusion of high vulnerability of the SMR to the scenario i.e. that the SMR cannot withstand the occourance of the given threat scenario and cannot be built in Israel without appropriate protection against a potential munition hit. 


\section{Acknowledgements}

The research was funded by the Ministry of Energy the State-of-Israel Grant No. 217-11-024. The authors wish to express their gratitude to the research accompanying persons: Dr. Ehud Azoulay and Dr. Yoram Luninski.

\section{References}

[1] Ronen Y. Nuclear reactor nuclear energy - past and future. 1st. ed. Israel: Department of Defense, State of Israel; 1987.

[2] Shohet IM, Ornai D, Gal E, Ronen Y, Vidra M. Protective alternatives of SMR against extreme threat scenario - A preliminary risk analysis. 27 Conference of Israel Nuclear Societies in Israel (INS), Israel. 2014:55.

[3] Ornai D, Gal E, Ronen Y, Shohet IM. Nuclear power plant (NPP) protection alternatives against hostile events and their safety \& operational implications. Ben-Gurion University of the Negev. 2014.

[4] Liao J, Kucukboyaci VN, Wright RF. Development of a LOCA safety analysis evaluation model for the westinghouse small modular reactor. Ann Nucl Energy. 2016;98:61-73.

[5] Gangloff, W., Westinghouse AP600 advanced nuclear plant design, , November, 30 - December, 41998 1999, International Atomic Energy Agency Published as IAEA-TECDOC-1117, Vienna, December 1999, p. $313 \mathrm{ff}$

[6] Smith MC, Wright RF. Westinghouse small modular reactor passive safety system response to postulated events. Proceedings of ICAPP' 12 Chicago, USA, June 24-28, 2012 Paper 12157. 2012.

[7] Reyes JN. NuScale plant safety in response to extreme events. Nuclear Technology. 2012;178(2):153-163. http://www.tandfonline.com/doi/abs/10.13182/NT12-A13556. https://doi.org/10.13182/NT12-A13556.

[8] NuScale. Design structures, components, equipment, and systems. https://www.nrc.gov/docs/ML1910/ML19102A109.pdf. Updated 2018. Accessed February 25, 2020.

[9] Shohet IM, Ornai D, Levy R, et al. A methodology of risk assessment, management and coping actions for nuclear power plant hit by high explosive warheads. Ben-Gurion University of the Negev. 2018:196.

[10] Lo Frano R, Forasassi G. Preliminary evaluation of aircraft impact on a near term nuclear power plant. Nuclear Engineering and Design. 2011;241(12):5245-5250. https://doi.org/10.1016/j.nucengdes.2011.08.079.

[11] Saberi R, Alinejad M, Mahdavi M, Sepanloo K. Numerical analysis of nuclear power plant structure subjected to aircraft crash. Int $J$ Adv Struct Eng. 2017;9(4):341-352. https://doi.org/10.1007/s40091-017-0170-0.

[12] James RJ, Parker J, Hill R, Wiesner J, Groome J. Aircraft impact considerations for NuScale SMR plant design. Proceedings of the ASME 2011 Small Modular Reactors Symposium SMR 2011. 2011;54730:395-404.

[13] Riera JD. On the stress analysis of structures subjected to aircraft impact forces. Nuclear Engineering and Design. 1968;8(4):415426. https://doi.org/10.1016/0029-5493(68)90039-3

[14] Markou G, Genco F. Seismic assessment of small modular reactors: NuScale case study for the 8.8Mw earthquake in chile. Nuclear Engineering and Design. 2019;342:176-204. https://doi.org/10.1016/j.nucengdes.2018.12.002.

[15] Nuscale. NuScale standard plant design certification Application Chapter one introduction and general description of the plant PART 2 - TIER 2. Chapter 19 Probabilistic Risk Assessment and Severe Accident Evaluation Nuclear Regulatory Commission (NRC). 2016:389. 